This is an author produced version of a paper published in Dalton Transactions.

This paper has been peer-reviewed but may not include the final publisher proof-corrections or pagination.

Citation for the published paper:

Bajnóczi, Éva G.; Czeglédi, Eszter; Kuzmann, Ernő; Homonnay, Zoltán; Bálint, Szabolcs; Dombi, György; Forgo, Péter; Berkesi, Ottó; Pálinkó, István; Peintler, Gábor; Sipos, Pál and Persson, Ingmar. (2014) Speciation and structure of lead(II) in hyper-alkaline aqueous solution. Dalton Transactions. Volume: 43, pp 17971-17979. http://dx.doi.org/10.1039/C4DT02706J.

Access to the published version may require journal subscription. Published with permission from: Royal Society of Chemistry.

Epsilon Open Archive http://epsilon.slu.se 


\title{
Speciation and structure of lead(II) in hyper-alkaline aqueous solution
}

\author{
Éva G. Bajnóczi, ${ }^{\text {a,f }}$ István Pálinkó, ${ }^{\text {b,f }}$ Tamás Körtvélyesi, ${ }^{\text {c }}$ Szabolcs Bálint, ${ }^{\text {d }}$ Imre Bakó, ${ }^{\text {d }}$ Pál Sipos ${ }^{\text {a,f,* }}$ and \\ Ingmar Persson ${ }^{\mathrm{e}}$ *
}

Received (in $X X X, X X X)$ XthXXXXXXXXX 20XX, Accepted Xth $X X X X X X X X X 20 X X$

${ }_{5}$ DOI: 10.1039/b000000x

\begin{abstract}
The identity of the predominating lead(II) species in hyperalkaline aqueous solution has been determined by Raman 10 spectroscopy, and ab initio quantum chemical calculations, and its structure has been determined by EXAFS. The observed and calculated Raman spectra for the $\left[\mathrm{Pb}(\mathrm{OH})_{3}\right]^{-}$complex are in agreement while they are different for two-coordinated complexes and complexes containing $\mathrm{Pb}=\mathrm{O}$ double bonds.

15 Predicted bond lengths are also consistent with the presence of $\left[\mathrm{Pb}(\mathrm{OH})_{3}\right]^{-}$and exclude the formation of $\mathrm{Pb}=\mathrm{O}$ double bond(s). These observations together with experimentally established analogies between lead(II) and tin(II) in hyper-alkaline aqueous solutions suggest, that the last stepwise hydroxido complex of 20 lead(II) is $\left[\mathrm{Pb}(\mathrm{OH})_{3}\right]^{-}$. The $\mathrm{Pb}-\mathrm{O}$ bond distance in the $\left[\mathrm{Pb}(\mathrm{OH})_{3}\right]^{-}$ complex as determined is remarkably short, $2.216 \AA$, and has low symmetry as no multiple back-scattering is observed. The $\left[\mathrm{Pb}(\mathrm{OH})_{3}\right]^{-}$complex has most likely trigonal pyramidal geometry as all reported three-coordinated lead(II) complexes in the solid

25 state. From single crystal X-ray data, the bond lengths for Ocoordinated lead(II) complexes with low coordination numbers are spread over an unusually wide interval, $2.216-2.464 \AA$ for $N=3$. The $\mathrm{Pb}-\mathrm{O}$ bond distance is at the short side and within the range of three coordinated complexes, as also observed for the 30 trihydroxidostannate(II) complex indicating that hydroxide ion forms short bonds to $\mathrm{d}^{10} \mathrm{~s}^{2}$ metal ions with occupied anti-bonding orbitals.
\end{abstract}

\section{Introduction}

The most common oxidation state of lead in nature is +2 . Because 35 of its high toxicity, ${ }^{1}$ the knowledge of hydrolytic equilibria of lead(II) is of high relevance, both in natural waters and living organisms, ${ }^{2}$ and in aqueous solutions with high $\mathrm{pH}$, which are of industrial importance. ${ }^{3}$ Upon hydrolysis in dilute aqueous solutions in the range of $2<\mathrm{pH}<13$, lead(II) forms mononuclear 40 complexes with the stoichiometry of $[\mathrm{Pb}(\mathrm{OH})]^{+},\left[\mathrm{Pb}(\mathrm{OH})_{2}\right]^{0}$ and $\left[\mathrm{Pb}(\mathrm{OH})_{3}\right]^{-} ., 5$ Furthermore, at higher lead(II)-concentrations, the formation of polynuclear complexes as $\left[\mathrm{Pb}_{3}(\mathrm{OH})_{4}\right]^{2+}$, $\left[\mathrm{Pb}_{4}(\mathrm{OH})_{4}\right]^{4+}$ and $\left[\mathrm{Pb}_{6} \mathrm{O}(\mathrm{OH})_{6}\right]^{4+}$ has been reported as well. ${ }^{4,5}$

Much controversy surrounds the composition of the $\mathrm{Pb}(\mathrm{II})$ 45 complex(es) formed in hyper-alkaline aqueous solution. The simplest speciation picture includes the exclusive formation of the $\left[\mathrm{Pb}(\mathrm{OH})_{3}\right]^{-}$even at the very alkaline end of the $\mathrm{pH}$-scale and was supported by potentiometric, ${ }^{6}$ polarographic, ${ }^{7-9}$ and solubility $^{10,11}$ measurements. Ultracentrifuge ${ }^{12}$ and light 50 scattering $^{13}$ data were, however, interpreted in terms of the formation of $\left[\mathrm{Pb}(\mathrm{OH})_{4}\right]^{2-}$ complexes and from potentiometric titrations using lead amalgam electrode the formation of the $\left[\mathrm{Pb}(\mathrm{OH})_{6}\right]^{4-}$ complex was suggested. ${ }^{14}$ In a recent work of Perera et $a l .{ }^{15}$ the formation of the lead(II)-hydroxido complex with the 55 stoichiometry of 1:4 was deduced, primarily from combined $\mathrm{pH}$ spectrophotometric measurements. From Raman spectra, the formation of the two-coordinated complex, $\left[\mathrm{PbO}_{2}\right]^{2-}$, was also suggested. However, the structure of the complex(es) formed in these hyper-alkaline conditions was not determined 60 experimentally.

As the valence electron structure of lead(II) is analogous to that of tin(II), therefore the hydrolysis of lead(II) in highly alkaline media is expected to have some similarities with tin(II). Unfortunately, the solubility of $\mathrm{Pb}(\mathrm{II})$ in hyper-alkaline solutions 65 was found to be insufficient to perform accurate $\mathrm{H}_{2} / \mathrm{Pt}$ potentiometric measurements, similar to those done for $\mathrm{Sn}(\mathrm{II}) .{ }^{16}$ Therefore some structural conclusions are based on the similarity of lead(II) and tin(II).

The main objective of the present work is to reveal the identity 70 and structure of lead(II) complex(es) present in hyper-alkaline aqueous solutions. To achieve this Raman spectroscopy and $a b$ initio quantum chemical calculations were used to determine the speciation of the predominating lead(II) complex, and $\mathrm{Pb}$ L-edge EXAFS to determine its structure.

\section{${ }_{75}$ Experimental section}

\section{Reagents and solutions}

Analytical grade sodium hydroxide, $\mathrm{NaOH}$ (ANALR NORMAPUR), was dissolved in distilled water with intensive stirring and cooling to prepare the alkaline stock solution. In this 80 way $\sim 50 \%(w / w) \mathrm{NaOH}$ solution is achievable; the concentration of the solution is $\sim 19 \mathrm{~mol} \cdot \mathrm{dm}^{-3}$. The concentration was calculated from the density of the solution, determined by a picnometer, according to literature procedures. ${ }^{17}$ The $\mathrm{Na}_{2} \mathrm{CO}_{3}$ is practically insoluble in such concentrated $\mathrm{NaOH}$ solutions, so after the 85 sedimentation of it and the vacuum filtration of the supernatant 
on a alkali-resistant filter, the carbonate concentration of the filtrate is less than $0.2 \%$ of the total alkalinity. ${ }^{18}$ The stock solution as well as the sample solutions were stored in caustic resistant Pyrex bottles with a tightly fitting screw-tops.

5 The lead(II) stock solution, $\quad C_{\mathrm{Pb}(\mathrm{II})}=1 \mathrm{~mol} \cdot \mathrm{dm}^{-3}$ and $C_{\mathrm{HNO} 3}=0.05 \mathrm{~mol} \cdot \mathrm{dm}^{-3}$, was prepared by dissolving analytical grade lead(II) nitrate, $\mathrm{Pb}\left(\mathrm{NO}_{3}\right)_{2}$ (Sigma Aldrich), in analytical grade nitric acid in order to avoid the hydrolysis of the lead(II) ions when diluted by distilled water. The caustic lead(II) solution 10 was prepared by adding the calculated amount of the lead(II) stock solution drop-wise to the $\mathrm{NaOH}$ solution, in a small Pyrex bottle, for which a custom-made screw-top was fabricated with two small holes for the argon gas in- and outlet and a bigger one for the addition of the lead(II) stock solution. The calculated 15 amount of the freshly prepared lead(II) stock solution was added drop-wise to $25 \mathrm{~mL}$ of the appropriately diluted $\mathrm{NaOH}$ solution with continuous and intense argon bubbling through the sample and stirring. The $\mathrm{NaOH}$ solutions were diluted by weight from the concentrated stock solution.

\section{${ }_{20} \mathrm{X}$-ray absorption measurements}

The X-ray absorption spectra for lead were collected at the wiggler beam-line I811 at MAX-lab, Lund University, Sweden, using the MAX II storage ring operating at $1.5 \mathrm{GeV}$ and a maximum current of $250 \mathrm{~mA}$. The maximum flux on the sample 25 is $5 \times 10^{11}$ at $9 \mathrm{keV}$ on a $(0.5 \mathrm{~mm})^{2}$ surface area. The measurements were performed in fluorescence mode at the lead $\mathrm{L}_{3}$-edge. The fluorescence mode was used because the total absorption of these solutions is very large in comparison to absorption of lead, also at the energy of the $\mathrm{L}_{3}$-edge. This causes 30 that the noise level is transmission becomes high, while signal to noise ratio is better for the fluorescence mode data. It can however be seen in the small amplitude reduction factor $\left(\mathrm{S}_{0}{ }^{2}\right)$ that the self-absorption is very large for $16 \mathrm{M} \mathrm{NaOH}$ solution (0.51), larger, but still small $(0.71)$ for the $8 \mathrm{M} \mathrm{NaOH}$ solution, while it 35 is normal for the $4 \mathrm{M} \mathrm{NaOH}$ solution (1.01); the theoretical value shall be in the range of 0.9-1.0. With a lower lead(II) concentration the fraction lead absorption of the total absorption should be even smaller and thereby the signal to noise level would be even lower, which should result in meaningless data.

40 The energy scales of the X-ray absorption spectra were calibrated by assigning the first inflection point of the lead $\mathrm{L}_{3}$ edges of metallic lead foil to $13038.0 \mathrm{eV} .{ }^{19}$ The samples were measured in cells which were made of a $1.5 \mathrm{~mm}$ Teflon spacer and $6 \mu \mathrm{m}$ polypropylene X-ray film hold together with titanium frames.

${ }_{45}$ The analysis of the data was performed with the EXAFSPAK ${ }^{20}$ and $\mathrm{FEFF}^{21}$ program packages allowing the determination the structure parameters of the local coordination around lead(II).

\section{FT-Raman spectroscopy}

Raman spectra were recorded on a BIO-RAD Digilab Division 50 dedicated FT-Raman spectrometer equipped with liquid nitrogen cooled germanium detector and $\mathrm{CaF}_{2}$ beamsplitter. The excitation line was provided by a Spectra Physics T10-106C Nd:YVO ${ }_{4}$ laser at $1064 \mathrm{~nm}$. The spectra were recorded in the range $3600-$ $100 \mathrm{~cm}^{-1}$ with $4 \mathrm{~cm}^{-1}$ resolution. 4096 scans were collected and 55 averaged for each spectrum. The excitation power was $280 \mathrm{~mW}$ at the sample position. The spectrometer was controlled by using BIO-RAD Win IR 3.3 software. The samples were placed in a
$1 \mathrm{~cm}$ path length quartz cuvette and recorded at roomtemperature. Data were processed by SpekWin software and the 60 fitting of the Lorentzian curves was performed with QtiPlot.

\section{Computational methods}

The complexes studied by computational methods included $\left[\mathrm{Pb}(\mathrm{OH})_{3}\right]^{-},[\mathrm{PbO}(\mathrm{OH})]^{-},\left[\mathrm{PbO}_{2}\right]^{2-},\left[\mathrm{PbO}(\mathrm{OH})_{2}\right]^{2-}, \mathrm{Pb}(\mathrm{OH})_{2}$ and $\left[\mathrm{Pb}\left(\mathrm{H}_{2} \mathrm{O}\right)_{3}\right]^{2+}$. Optimizations and frequency analyses were ${ }_{65}$ performed using the GAUSSIAN 09 program $^{22}$ with density functional theory (DFT) at the B3LYP level. The heavy atom represented with SDD basis set, which takes into account the scalar relativistic effects. For the other elements the $6-31+\mathrm{G}^{* *}$ has been applied. Solvents effects were handled through a 70 polarizable continuum, according to the method implemented in the PCM-SCRF (self-consistent reaction field) procedure in the Gaussian program. In some cases explicitly the hydration shell of these complexes has been taken account. However, the calculated properties do not change significantly compared to the PCM 75 method, so we do not discuss those results.

\section{Results and discussion}

\section{Raman spectroscopy and quantum chemical calculations}

The Raman spectrum of a lead(II) containing aqueous solution $\left(C_{\mathrm{Pb}\left(\mathrm{NO}_{3}\right)_{2}}=0.1 \mathrm{M}\right)$ with $C_{\mathrm{NaOH}}=4.0 \mathrm{M}$ has been recorded. A 80 strong peak at $\sim 424 \mathrm{~cm}^{-1}$ and a shoulder at $\sim 355 \mathrm{~cm}^{-1}$ is observed on the spectrum, which correspond to $\mathrm{Pb}-\mathrm{O}$ asymmetrical and symmetrical stretching vibrations, respectively. A strong signal due to the symmetric stretching mode of $\mathrm{NO}_{3}{ }^{-}$ion was also observed at $1048 \mathrm{~cm}^{-1}$. The Raman spectrum of a solution with 85 similar composition as the one is reported in ref. 15, with a peak at $419 \mathrm{~cm}^{-1}$ and a shoulder at $377 \mathrm{~cm}^{-1}$ was reported. These values are in good agreement with those in this study. In ref. 15 the sample has been prepared from $\mathrm{PbO}(\mathrm{s})$ and a signal at $1064 \mathrm{~cm}^{-1}$ was assigned to the species $\left[\mathrm{PbO}_{2}\right]^{2-}$. It is important to 90 note, that there are obvious similarities between the Raman spectra of hyper-alkaline solutions containing tin(II) and lead(II). In the former, a strong peak was found at $\sim 430 \mathrm{~cm}^{-1}$ and a weak at $\sim 490 \mathrm{~cm}^{-1}$, and were assigned to the species $\left[\mathrm{Sn}(\mathrm{OH})_{3}\right]^{-}$ complex. ${ }^{16}$ The lower wave numbers for the lead(II) complex is 95 expected due to weaker electrostatic contribution to the $\mathrm{Pb}-\mathrm{O}$ due to larger ionic radius.

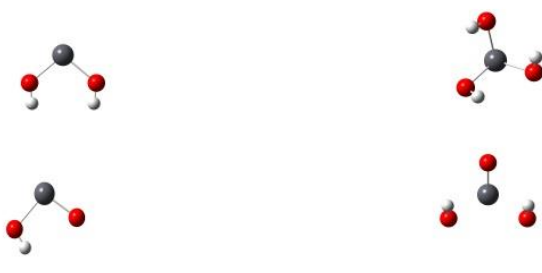

Fig. 1. Ball and stick models for the oxido-hydroxido complexes of $\mathrm{Pb}$ (II) 100 studied. 
Table 1.Comparison of the experimentally found and calculated bond lengths and Raman band positions for various hypothetic oxidohydroxido complexes of $\mathrm{Pb}$ (II).

\begin{tabular}{|c|c|c|c|c|}
\hline & $\mathbf{N}$ & $\begin{array}{c}r_{\mathrm{Pb}-\mathrm{O}}^{a} \\
(\AA)\end{array}$ & $\begin{array}{c}r_{\mathrm{Pb}=\mathbf{0}}{ }^{b} \\
(\AA)\end{array}$ & $\begin{array}{l}\text { Raman peaks } \\
\left(\mathbf{c m}^{-1}\right)\end{array}$ \\
\hline \multicolumn{5}{|c|}{ Experimental } \\
\hline sample & - & \multicolumn{2}{|c|}{2.216} & $\begin{array}{c}355 \mathrm{w}, 424 \mathrm{~s}^{c} \\
\left(377 \mathrm{w}, 419 \mathrm{sd}^{d}\right)\end{array}$ \\
\hline \multicolumn{5}{|c|}{$\mathrm{ab}$ initio } \\
\hline$\left[\mathrm{Pb}(\mathrm{OH})_{3}\right]^{-}$ & 3 & 2.232 & - & $370 \mathrm{~s}, 413 \mathrm{~s}$ \\
\hline$\left[\mathrm{PbO}(\mathrm{OH})_{2}\right]^{2-}$ & 3 & 2.430 & 2.050 & $222 \mathrm{w}, 256 \mathrm{w}, 523 \mathrm{~s}$ \\
\hline$[\mathrm{PbO}(\mathrm{OH})]^{-}$ & 2 & 2.256 & 1.990 & $363 w, 603 s$ \\
\hline$\left[\mathrm{PbO}_{2}\right]^{2-}$ & 2 & - & 2.103 & $203 w, 452 s, 496 s$ \\
\hline $\mathrm{Pb}(\mathrm{OH})_{2}$ & 2 & 2.123 & - & $459 w, 488 s$ \\
\hline$\left[\mathrm{Pb}\left(\mathrm{H}_{2} \mathrm{O}\right)_{3}\right]^{2+}$ & 3 & 2.440 & - & $261 w, 291 w$ \\
\hline
\end{tabular}

w: weak; s: strong; ${ }^{a} \mathrm{~Pb}-\mathrm{O}$ single bond; ${ }^{b} \mathrm{~Pb}=\mathrm{O}$ double bond; ${ }^{c}$ current 5 work; ${ }^{d}$ data taken from ref. 15

Quantum mechanical calculations were performed to obtain proposed bond lengths and Raman band positions for the complexes with structures shown in Figure 1. The results of these 10 calculations are summarized in Table 1.

As expected, the calculated bond lengths for $\mathrm{Pb}-\mathrm{O}$ single bonds are significantly longer (2.23-2.43 $\AA$ ), than those of $\mathrm{Pb}=\mathrm{O}$ double bonds (1.99-2.10 $\AA$ ). The calculated bond length for single bonds is very close to that obtained experimentally. On this ground, the 15 formation of the fully dehydrated species $\left[\mathrm{PbO}_{2}\right]^{2-}$ can be ruled out. If there were a mixed oxido-hydroxido complex, the two different bond lengths would be present in a single species. Since the exchange of the $\mathrm{H}^{+}$between the two oxygen atoms is slow comparing to the EXAFS timescale, therefore two distinct peaks 20 should be seen in case of $[\mathrm{PbO}(\mathrm{OH})]^{-}$, which is obviously not the case (see Fig. 2 (A) and Table 1). On that ground $\left[\mathrm{PbO}(\mathrm{OH})_{2}\right]^{2-}$ and $[\mathrm{PbO}(\mathrm{OH})]^{-}$can be discounted and only the $\left[\mathrm{Pb}(\mathrm{OH})_{3}\right]^{-}$ complex is the only reasonable lead(II) complex present hyperalkaline aqueous solution.

${ }_{25}$ The observed and calculated Raman spectra (Table 1) also support the exclusive formation of $\left[\mathrm{Pb}(\mathrm{OH})_{3}\right]^{-}$. The calculated Raman peak positions for this species almost perfectly match with those obtained here and in previous studies. On the other hand, the band positions for the other species show no 30 resemblance to the observed one and can therefore be excluded.

\section{Determination of the $\left[\mathrm{Pb}(\mathrm{OH})_{3}\right]^{-}$complex in hyper-alkaline aqueous solution}

EXAFS measurements were carried out on aqueous samples 35 containing $0.2 \mathrm{~mol} \cdot \mathrm{dm}^{-3}$ lead(II) in $4.0,8.0$ and $16.0 \mathrm{~mol} \cdot \mathrm{dm}^{-3}$ $\mathrm{NaOH}$. The results are given in Table 2 . No change in the local structure around lead(II) was observed with changing hydroxide concentration, and there was only one kind of species detected, Figure 2. (The $\mathrm{L}_{3}$-edge XANES spectra are also shown on 40 Fig. S1, but they were not fitted, as the theory for fitting the $\mathrm{L}_{3^{-}}$ edge XANES data is not yet on such level that accurate analysis can be made.) In this species, the $\mathrm{Pb}-\mathrm{O}$ bond distance was determined to be $2.216 \AA$. It is indeed shorter than the average $\mathrm{Pb}-\mathrm{O}$ bond distance for the three-coordinated lead(II) complexes 45 with O-donor ligands, $(2.318 \AA$, calculated as the average of 10 known structures). However, it is still within the interval of the observed bond distances. For lead(II), to the best of our knowledge, the structure of only one O-coordinated complex with $N=2$ has been reported so far (with $r_{\mathrm{Pb}-\mathrm{O}}=2.189 \AA$ ). The fitting 50 of the experimental EXAFS data was carried out with holding the coordination number fixed at 3 . However, similarly to that observed for analogous systems containing $\mathrm{Sn}(\mathrm{II}),{ }^{16}$ good agreement between the observed and calculated data was achieved by assuming $N=2$. On the other end, the case for $N=4$ 55 was discounted on the ground, that the experimentally obtained $r_{\mathrm{Pb}-\mathrm{O}}=2.216 \AA$ is far out of the bond length interval obtained for solid complexes with $N=(2.30-2.46 \AA)$. Therefore, the formation of any kind of 4-coordinate lead(II)-hydroxido complex, e.g., $\left[\mathrm{Pb}(\mathrm{OH})_{4}\right]^{2-}$, in hyper-alkaline aqueous solution can be ruled out.
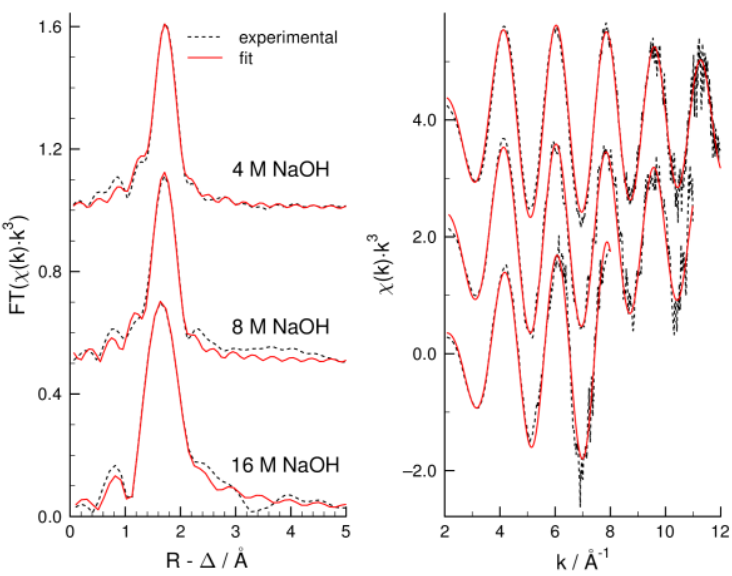

60

Fig. 2. The experimental and the fitted Fourier-transform of the $k^{3}$ weighted EXAFS data of the alkaline lead(II) samples: $\mathrm{Pb} 20 \_4, \mathrm{~Pb} 20 \_8$ and $\mathrm{Pb} 20 \_16(\mathrm{~A})$; the experimental and the fitted $k^{3}$-weighted EXAFS data, respectively (B). The noise level in the $16 \mathrm{M}$ solution is 65 unfortunately too high above $\mathrm{k}=8 \AA^{-1}$ for reasonable refinement of data, thus it is not shown on the figure.

Table 2. Composition of hyper-alkaline aqueous lead(II) samples studied expressed in total molar concentrations, and the structure parameters in the refinements of the EXAFS data collected at ambient room temperature 70 using the EXAFSPAK program package including number of $\mathrm{Pb}-\mathrm{O}$ bond distances, $N$, mean Sn-O bond distance, $r / \AA$, and Debye-Waller factor coefficient, $\sigma^{2} / \AA^{2}$, the threshold energy, $E_{\mathrm{o}} / \mathrm{eV}$, the amplitude reduction factor the goodness, $S_{0}^{2}$, the goodness of fit, $F / \%$, as expressed in the EXAFSPAK program package, ref. 20.

\begin{tabular}{c|ccc}
\hline$N=\mathbf{3}$ & $\mathrm{Pb} 20 \_4$ & $\mathrm{~Pb} 20 \_8$ & $\mathrm{~Pb} 20 \_16$ \\
\hline$C_{\mathrm{NaOH}}$ & 4 & 8 & 16 \\
$C_{\mathrm{Pb}(\mathrm{II})}$ & 0.20 & 0.20 & 0.20 \\
$S_{\mathrm{o}}{ }^{2}$ & 1.01 & 0.71 & 0.51 \\
$r$ & 2.216 & 2.222 & 2.216 \\
$\sigma^{2}$ & 0.033 & 0.033 & 0.021 \\
$E_{\mathrm{o}}$ & 13064.0 & 13064.7 & 13065.0 \\
$F$ & 18.5 & 25.7 & 22.0
\end{tabular}

75 From extended X-ray absorption fine structure spectroscopy (EXAFS), bond lengths ( $r_{\mathrm{Pb}-\mathrm{O}}$ ) can be more accurately determined than the corresponding coordination numbers $(N) .^{23}$ The relationship between bond distance and coordination number may be extracted from single crystal X-ray data. Therefore in most 80 cases (i.e., for transition metal complexes) this relationship can be used to accurately estimate the coordination number from the observed bond distance. ${ }^{23,24}$ The $r_{\mathrm{Pb}-\mathrm{O}}$ and $N$ values of crystalline solid O-coordinated lead(II) compounds were collected from the Inorganic Crystal Structure Database ${ }^{25}$ and the Cambridge ${ }_{85}$ Crystal Structure Database ${ }^{26}$, and were published in a previous 
$\operatorname{paper}^{27}$ (except for those relating to complexes with $N=3$ and the only one example for $N=2$, shown in Table S1). The $r_{\mathrm{Pb}-\mathrm{O}} v s . N$ data collected are shown on Figure 3. The bond lengths for Ocoordinated lead(II) complexes, in particular for those with low 5 coordination numbers are spread over an unusually wide interval (e.g., 2.216-2.464 $\AA$ for $N=3$ ). This is most likely due to the stereo-chemical impact of the occupied anti-bonding orbitals of lead(II). ${ }^{28-31}$

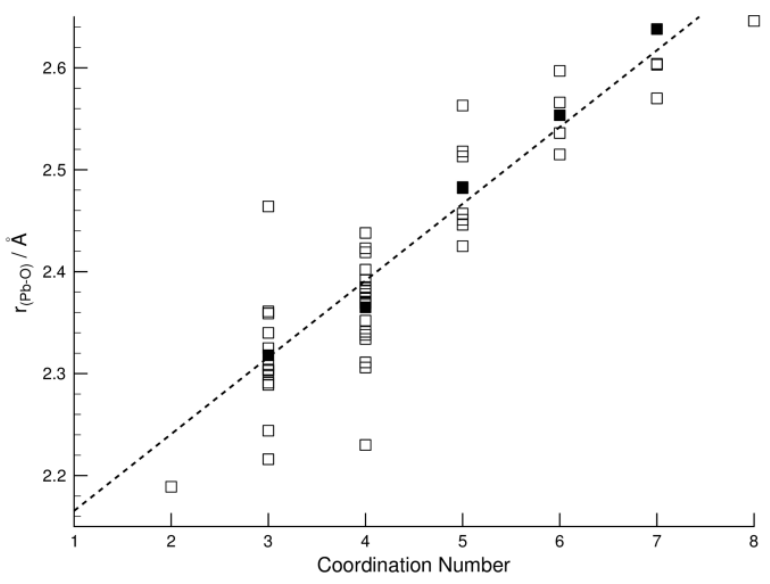

$10 \quad$ Fig. 3. Summary of mean bond distances in O-coordinated lead(II) compounds (details in Tables S1, and ref.26), and the relationship between the mean $\mathrm{Pb}-\mathrm{O}$ bond lengths and the coordination. The filled symbols stand for the average values. The dashed line represents the linear trend-line of the mean $\mathrm{Pb}-\mathrm{O}$ bond distances as function of coordination number.

\section{Conclusions}

In summary, EXAFS spectroscopic measurements show that only one kind of lead(II) complex is present in strongly alkaline aqueous solutions, containing $4.0-16.0 \mathrm{~mol} \cdot \mathrm{dm}^{-3} \mathrm{NaOH}$. The 20 predominating complex is the mononuclear $\left[\mathrm{Pb}(\mathrm{OH})_{3}\right]^{-}$with short $\mathrm{Pb}-\mathrm{O}$ bond length, $2.216 \AA$. This is just within the range of bond distances observed for three-coordinate lead(II) complexes. The agreement between the calculated Raman spectrum of $\left[\mathrm{Pb}(\mathrm{OH})_{3}\right]^{-}$ and the experimentally observed one fully supports the exclusive, 25 or at least predominant, presence of this mononuclear complex in these hyper-alkaline aqueous solutions.

\section{Acknowledgment}

Research leading to this contribution was supported by the National Research Fund of Hungary through OTKA 83889. Éva ${ }_{30} \mathrm{G}$. Bajnóczi would like to thank the Campus Hungary Scholarship of the Balassi Institute which financed a five week short term study at the Department of Chemistry and Biotechnology, Swedish University of Agricultural Sciences, Uppsala, Sweden. Portions of this research were carried out at 35 beam-line I811, MAX-lab synchrotron radiation source, Lund University, Sweden. Funding for the beam-line I811 project was kindly provided "The Knut och Alice Wallenbergs Stiftelse".

\section{Notes and references}

${ }^{a}$ Department of Inorganic and Analytical Chemistry, University of Szeged, 40 H-6720 Dóm tér 7., Szeged, Hungary.
${ }^{b}$ Department of Organic Chemistry, University of Szeged, H-6720 Dóm tér 8., Szeged, Hungary.

${ }^{c}$ Department of Physical Chemistry and Materials Science, University of Szeged, H-6720 Aradi vértanúk tere 1., Szeged, Hungary

$45{ }^{d}$ Institute of MolecularPharmacology, Research Centre

forNaturalSciences, HungarianAcademy of Sciences, Pusztaszeri út 59-67, H-1025 Budapest, Hungary

${ }^{e}$ Department of Chemistry and Biotechnology, Swedish University of Agricultural Sciences, SE-750 07, Uppsala, Sweden

${ }_{50}^{f}{ }^{f}$ Materials and Solution Structure Research Group, Institute of Chemistry, University of Szeged H-6720 Aradi vértanúk tere 1., Szeged, Hungary

*Corresponding authors: sipos@chem.u-szeged.hu, Ingmar.persson@slu.se

$55 \dagger$ Electronic Supplementary Information (ESI) available: bond lengths and angles found for $\mathrm{N}=3$ and $2 \mathrm{O}$-coordinated $\mathrm{Pb}$ (II) complexes.. See DOI: $10.1039 / \mathrm{b} 000000 \mathrm{x} /$

1 J. J. Brean and C. R. Stroup, Lead Poisoning: Exposure, Abatement, Regulation, CRC Press, USA, 1995.

2 H. Casas and H. Sordo, Lead Chemistry, Analytical Aspects, Environmental Impacts and Health Effect, Elsevier: Amsterdam, 2006.

3 M. I. Jeffrey, I. M. Ritchie and S. R. Labrooy, in R. Woods, F. M. Doyle, P. E. Richardson (eds.), Electrochemistry in Mineral and Metal Propcessing $I V$.", Electrochemistry Society: Pennington, NJ, USA, 1996. p. 284.

4 A. E. Martell; R. M. Smith, Critical Stability Constants; Plenum Press: London , 1975.

705 C. F. Baes and R. E. Mesmer, The Hydrolysis of Cations, John Wiley \& Sons: NewYork, 1976; ch 15.4

6 B. Carell and Å. Olin, Acta Chem. Scand., 1960, 14, 1999-2008.

7 A. A. Vlcek, Chem. Listy, 1954, 48, 1474-1484.

8 N. V. Aksel'rud, Russ. J. Inorg. Chem., 1958, 3, 23-36.

759 A. I. Karnaukhov, V. E. Kosmatyi and V. V. Grinevich, Ukr. Khim. Zh., 1984, 50, 1086-1088.

10 A. B. Garrett, S. Vellenga and C. M. Fontana, J. Am. Chem. Soc., 1939, 61, 367-373.

$11 \mathrm{~J} . \mathrm{W}$. Mellor, „A Comprehensive Treatise on Inorganic and Theoretical Chemsitry, Vol. VII. 'Longman, London, UK, 1970.

12 J. S. Johnson and K. A. Kraus, J. Am. Chem. Soc, 1959, 81, 15691572.

13 B. Pokric and Z. Pucar, J. Inorg. Nucl. Chem., 1973, 35, 1987-1993.

14 D. Ferri and F.Salvatore, Ann. Chim., 1989, 79, 1-13.

8515 N. Perera, G. T. Hefter and P. Sipos,Inorg. Chem., 2001, 40, $3974-$ 3978.

16 É. G. Bajnóczi, E. Czeglédi, E. Kuzmann, Z. Homonnay, Sz. Bálint, Gy. Dombi, P. Forgo, O. Berkesi, I. Pálinkó, G. Peintler, P. Sipos and I. Persson, Dalton. Trans., submitted

9017 P. Sipos, G. T. Hefter and P. M. May, J. Chem. Eng. Data 2000, 45, 613-616.

18 P. Sipos, G. T. Hefter, P. M. May, The Analyst, 2000, 125, 955-958.

19 A. Thompson, D. Attwood, E. Gullikson, M. Howells,K-J. Kim, J. Kirz, J. Kortright, I. Lindau, Y. Liu, P. Pianetta, A. Robinson, J.

95 Scofield, J. Underwood, G. Williams and H. Winick, X-ray data booklet, Lawrence Berkley National Laboratory, 2009.

20 G. N. George and I. F. Pickering, EXAFSPAK - A suite of Computer Programs for Analysis of X-ray absorption spectra, Stanford Synchrotron Radiation Laboratory, Stanford, CA, 1995. 100 http://www-ssrl.slac.stanford.edu/exafspak.html (accessed July 2014)

21 S. I. Zabinsky, J. J. Rehr, A. Ankudinov, R. C. Albers and M. Eller, J. Phys. Rev. B, 1995, 52, 2995-3009.

22 Gaussian 09, Revision B.01 by: M. J. Frisch, G. W. Trucks, H. B. Schlegel, G. E. Scuseria, M. A. Robb, J. R. Cheeseman, G. Scalmani, V. Barone, B. Mennucci, G. A. Petersson, H. Nakatsuji, M. Caricato, X. Li, H. P. Hratchian, A. F. Izmaylov, J. Bloino, G. Zheng, J. L. Sonnenberg, M. Hada, M. Ehara, K. Toyota, R. Fukuda, J. Hasegawa, M. Ishida, T. Nakajima, Y. Honda, O. Kitao, H. Nakai, T. Vreven, J. A. Montgomery, J. E. Peralta, F. Ogliaro, M. Bearpark, J. J. Heyd, E. Brothers, K. N. Kudin, V. N. 
Staroverov, R. Kobayashi, J. Normand, K. Raghavachari, A. Rendell, J. C. Burant, S. S. Iyengar, J. Tomasi, M. Cossi, N. Rega, J. M. Millam, M. Klene, J. E. Knox, J. B. Cross, V. Bakken, C. Adamo, J. Jaramillo, R. Gomperts, R. E. Stratmann, O. Yazyev, A.

5 J. Austin, R. Cammi, C. Pomelli, J. W. Ochterski, R. L. Martin, K. Morokuma, V. G. Zakrzewski, G. A. Voth, P. Salvador, J. J. Dannenberg, S. Dapprich, A. D. Daniels, Farkas, J. B. Foresman, J. V. Ortiz, J. Cioslowski and D. J. Fox

23 I. Persson, M. Sandström, H. Yokoyama and M. Chaudhry, Z. Naturforsch., Sect. A. 1995, 50, 21-37.

24 R. D. Shannon, Acta Crystallogr., Sect. A 1976, 32, 751-767.

25 Inorganic Crystal Structure Database; FIZ Karlsruhe, 2013.

26 F. H. Allen, Acta Crystallogr., Sect. B 2002, 58, 380-388.

27 I. Persson, K. Lyczko, D. Lundberg, L. Eriksson and A. Placzek, 15 Inorg. Chem. 2011, 50, 1058-1072.

28 A.-V. Mudring, Inorganic Chemistry in Focus, III. ed., Wiley-VCH Verlag: Weinheim, 2006

29 A.-V. Mudring, F. Rieger, Inorg. Chem. 2005, 44, 6240-6243.

30 A. Walsh, G. W. Watson, J. Solid State Chem. 2005, 178, 1422-1428.

2031 A.-V. Mudring, Eur. J. Inorg. Chem. 2007, 882-890, and references therein. 